\title{
A Survey on Equivalence Modeling for Large-Scale Photovoltaic Power Plants
}

\author{
Pingping Han ${ }^{1}$, Zihao Lin ${ }^{1} * *$ (D) , Lei Wang ${ }^{1}$, Guijun Fan ${ }^{1}$ and Xiaoan Zhang ${ }^{2}$ \\ 1 Anhui Provincial Laboratory of New Energy Utilization and Energy Conservation, \\ Hefei University of Technology, Hefei 230009, China; LH021211@163.com (P.H.); lwang_hf@126.com (L.W.); \\ Fan_fan1995@163.com (G.F.) \\ 2 Intelligent Manufacturing Institute, Hefei University of Technology, Hefei 230009, China; \\ zhangxiaoan@263.net \\ * Correspondence: LZH36566@163.com; Tel.: +86-182-2551-8660
}

Received: 27 April 2018; Accepted: 2 June 2018; Published: 6 June 2018

\begin{abstract}
Due to the huge data of large-scale photovoltaic (PV) power plants, the establishment of its equivalent model is more practical than a detailed model. In connection with the current research status, this paper reviews the steady-state equivalent model and transient equivalent model of PV power plants. The steady-state equivalent model is used for power flow calculation and static stability analysis. Transient equivalent models contain the single-machine equivalent model and the multi-machine equivalent models, which are used for the simulation analysis of large disturbances. The calculation of equivalent parameters and the equivalence of power collection system are briefly introduced. The conclusion and problems to be solved are put forward at the end. The establishment of the equivalent model simplifies the detailed model, which is convenient for the planning and simulation analysis of the PV power plant, and can also accurately characterize the operating characteristics of the PV power plant, which is of great significance.
\end{abstract}

Keywords: large-scale PV power plant; single-machine equivalent model; multi-machine equivalent models; equivalent parameters; power collection system

\section{Introduction}

The development of renewable energy sources such as solar energy and wind energy is an important measure for the transformation of energy structure. It has become the consensus of all countries in the world, and is also the general trend of global energy changes. The European Union once mentioned that by 2050, Europe's energy supply will entirely come from renewable energy sources without nuclear energy, and a complete replacement of conventional energy by renewable energy sources will be achieved [1]. Many countries are rich in solar energy resources and have advantages for the development of solar energy utilization, and so does China since the 13th Five-Year plan (the five-year plan, known as the outline of the five-year plan for the People's Republic of China's national economic and social development 2016-2020, is China's thirteenth five-year plan). With the rapid improvement of solar cell technology, the costs of solar cell production and PV power generation have declined rapidly. Under the support of various PV policies, the PV power market in China has continued to develop rapidly. In 2017, the cumulative installed capacity of PV power in China reached 130 million kW, and the target of the "13th Five-Year" plan was completed ahead of schedule [2]. China has invested a lot of energy in the construction of large-scale PV power plants.

The development of large-scale PV power plants is the focus of strategic research on renewable energy development [3,4]. A PV power generation system mainly works in the grid-connected mode. However, unlike conventional power plants, high-capacity PV power plants have a huge impact 
on the dynamic characteristics of the power grid and also have a significant impact on the safe and stable operation of the power grid $[5,6]$. Therefore, in view of the analysis of the grid-connected operation characteristics of large-scale PV power plants, scholars have carried out a large number of modeling studies on grid-connected PV power plants, including the model of the independent core components of PV systems [7-9] and the overall model of the system [10-12], most of which are based on detailed models of PV power plants. For small and medium PV power plants, detailed models can be established for simulations, however, large-scale PV power plants are usually made up of dozens or even hundreds of PV units. Establishing detailed models one by one greatly increases the complexity and the time of the simulation. Therefore, taking into account both the accuracy and simplification of PV power plant models, establishing equivalent models of large-scale PV power plants that equivalently replace the detailed models can accurately characterize the operation characteristics of large-scale PV power plants and also provide convenience for planning and analysis as well as meet the requirements of simulation and calculation.

The equivalent models of large-scale PV power plants include steady-state equivalent models and transient equivalent models [13]. Steady-state equivalent models are used for power flow calculations and static stability analysis, and can be further extended to the planning, scheduling, and evaluation of PV systems. Transient equivalence can simplify a large-scale system and reproduce the dynamic response characteristics, which is mainly used to solve the problem of the transient stability of the PV power system after fault disturbance [14,15].

Therefore, the purpose of this paper was to summarize the current status and achievements of the research on equivalent models of large-scale PV power plants so that more readers can understand the meaning of equivalence modeling and promote the idea of using equivalence modeling more widely. In addition, the paper also provides a reference for further research. In this paper, the composition of large-scale PV power plants is first introduced. Then, the steady-state equivalent models of PV power plants are described. The transient equivalent models of large-scale PV power plants are introduced in detail including the single-machine equivalent model and multi-machine equivalent models. Finally, the calculation of equivalent parameters and the equivalence of the power collection system are summarized.

\section{Composition of PV Power Plants}

Grid-connected PV power generation systems mainly consist of PV arrays, inverters, transformers, and other links of the network [16], as shown in Figure 1. A PV array consists of multiple PV cells in series and in parallel. The electricity generated by the PV array is delivered to the grid via inverters, filters, and transformers [17].

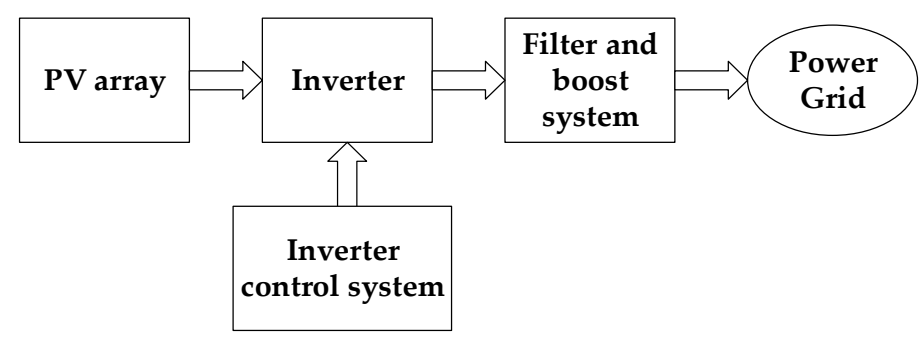

Figure 1. Block diagram of PV power generation systems.

Large-scale PV power plants are made up of dozens or even hundreds of PV power generation units and are quite different from small and medium PV power plants. Small and medium PV power plants are generally distributed power plants, which are mainly installed on the surface of the buildings such as in building integrated systems and rooftop PV systems, solving the problem of electricity consumption of users nearby [18]. The number of PV power generation units in small and medium PV power plants are small. The connection mode and the grid system are simple. Large-scale PV power 
plants are generally centralized power plants built on vast areas such as the desert surface that can make full use of the abundant and stable solar energy resources, and are connected to high-voltage transmission systems to supply long-distance loads [19]. The number of PV power generation units in large-scale PV power plant is large. It has large installed capacity, high voltage level, and a complex model structure and the equivalent model is needed to simplify it for simulation and computation.

\section{Steady-State Equivalent Model of PV Power Plants}

The change of environment makes the output of PV power generation random, fluctuating, and intermittent. A large-scale grid-connected PV power plant has great influence on the power flow and static stability of the connected power grid [20]. Establishing the steady-state equivalent model of large-scale PV power plant is of great significance to the planning and scheduling of power systems.

\subsection{The Type of Nodes}

According to the control strategy of PV power plant inverters, PV power units are usually treated as PQ (fixed active power output and reactive power output) nodes, PI (fixed active power output and constant grid-tied current) nodes, or PV (fixed active power output and voltage magnitude) nodes [21]. The summary is shown in Table 1.

Table 1. The type of nodes of PV power systems.

\begin{tabular}{ccc}
\hline Inverter Control Method & Node Type \\
\hline Current control & PI node to PQ node \\
\hline Constant power factor control & PQ node \\
\hline \multirow{2}{*}{ Voltage control } & Overvoltage & PV node \\
\cline { 2 - 3 } & Reactive power overflows & PQ node \\
\hline
\end{tabular}

When the PV inverter adopts current control, it is regarded as a PI node that outputs constant active power and current, and the reactive power output of the PI node can be obtained through each iteration of power flow calculation so that it can be regarded as a PQ node for processing [22]; For the PV inverter with constant power factor control, the reactive power output of the compensation device is related to the voltage amplitude of the node, and the PV power units can also be equivalent to the PQ nodes [23]; If a voltage-controlled inverter is used, it can be regarded as a PV node with constant active power and voltage. In the power flow calculation, the output voltage needs to be kept constant through reactive power regulation and optimization. However, during the iteration process, if reactive power exceeds its own capacity limit, the PV node needs to be converted into a PQ node for processing [24].

\subsection{The Overall Equivalent Model}

The overall model of the PV power plant is composed of a PV array, inverter, power collection system, and other components that are reasonably equivalent. Therefore, the overall model is less affected by the structure of specific components and is suitable for combination with power flow calculation and conversion about the type of nodes used for static voltage stability analysis. For example, the principle of power electronic transformation and instantaneous power balance can be applied to the overall steady-state model of a PV power plant. The state variables of the PV power plant and power grid are all taken into account in the power flow calculation, so as to comprehensively analyze the performance of the large-scale PV power plant during steady-state operation [25]. In [26], a PQ-coupled PV power flow calculation model was established. The output of a PV system can be regulated by setting the system modulation ratio and phase shift angle to make the PV power plant work in an approximately ideal state. In [27], it was considered that the analysis of static voltage 
stability is one-sided if a large-scale grid-connected PV power plant is simply equivalent to one node. Taking into account the internal components of the large-scale PV power plant and the network impedance, the overall steady-state equivalent model of a large-scale PV power plant was established. Bonfiglio proposed a static equivalence modeling method for a large-scale PV power plant that was grid-connected with a transmission/distribution network and could effectively evaluate the active power and reactive power losses in [28,29].

\section{Transient Equivalent Model of PV Power Plants}

The transient equivalent model is mainly used for large disturbance simulation analysis in power systems. According to the size of the PV power plant, inverter types, and research issues, the transient equivalent models can be divided into two types: single-machine equivalent model and multi-machine equivalent models. The single-machine equivalent model aggregates all PV power generation units into one unit. The multi-machine equivalent models are based on the same-tune idea [30], and the original system is divided into groups.

\subsection{The Single-Machine Equivalent Model of PV Power Plants}

The single-machine equivalent model does not consider grouping PV power plants, which means using one PV power generation unit to replace all units [31]. Single-machine equivalence can use capacity weighting and parameter identification. The two methods have their own characteristics and different application conditions. The comparison is summarized in Table 2.

Table 2. The single-machine equivalent method of PV power plants.

\begin{tabular}{clc}
\hline Equivalent Basis & \multicolumn{1}{c}{ Practical Application } & Results \\
\hline & Basic parameter aggregation [32,33] & \\
The equivalence of wind, PV and energy storage system [34] & Simple and easy to operate; \\
weighting & "Double multiplication" model that runs at full capacity [35] & Low precision; \\
& $\begin{array}{c}\text { Parameter aggregation of Thevenin equivalent model [36] } \\
\text { Parameter aggregation Norton equivalent model [37] }\end{array}$ & Ideal situation \\
\hline \multirow{2}{*}{$\begin{array}{c}\text { Parameter } \\
\text { identification }\end{array}$} & Crow search algorithm [38] & Heast Squares [39] \\
& Non-linear system identification technology [40] & Difficult to operate; \\
& & Actual situation \\
\hline
\end{tabular}

\subsubsection{Capacity Equal Weighted Method}

Ideally, it is considered that the types and parameters of the inverters in PV power plants are the same. All PV power generation units transmit the same power at the same moment. In this case, the entire PV power plant can be equivalent to one PV power generation unit according to the principle that the voltage at the grid connection point and the total output current are constant [32]. Based on the capacity equal weighted method, the following formulas can be used to obtain the equivalent parameters, including the equivalent rated capacity of inverters and transformers, the equivalent capacitance, the equivalent inductance and the equivalent impedance:

$$
\left\{\begin{array}{l}
S_{\mathrm{eq}}=\sum_{i=1}^{m} S_{i}, S_{\mathrm{T} \_\mathrm{eq}}=\sum_{i=1}^{m} S_{\mathrm{T} i} \\
C_{\mathrm{eq}}=\sum_{i=1}^{m} C_{i}, L_{\mathrm{eq}}=\frac{L_{i}}{m} \\
Z_{\mathrm{C}_{\mathrm{C}} \mathrm{eq}}=\frac{Z_{\mathrm{ci}}}{m}, Z_{\mathrm{T} \_\mathrm{eq}}=\frac{Z_{\mathrm{T} i}}{m}
\end{array}\right.
$$

In the formulas, $S_{i}, S_{\mathrm{T} i}$ are the rated capacity of the inverter and transformer in PV power unit $i$; $C_{i}, L_{i}$ are the capacitance and inductance in PV power unit $i ; Z_{\mathrm{c} i}, Z_{\mathrm{T} i}$ are the impedance of the inverter and transformer in PV power unit $i ; m$ is the number of $\mathrm{PV}$ power generation units; The subscript eq indicates the parameters of the equivalent $\mathrm{PV}$ power unit. 
Based on capacity weighting, Pan considered whether the PV cells were obstructed or not, idealizing the external characteristics of PV cells, and then identified the parallel number of equivalent PV modules in a PV power plant and established an equivalent model of the original system [33]. In the combined model of wind, PV, and energy storage system, the main work is to analyze the dynamic characteristics of each unit and establish the electromechanical transient model of each unit. Based on the principle of capacity equal weighting and loss invariance, the wind farm and PV power plant models were obtained [34]. Wang proposed a single-machine "double multiplication" model that ran at full capacity and applied it to more severe operating conditions, which reduced the equivalence error caused by different disturbances in practical projects [35].

In [36], Thevenin equivalence and inertia adjustment were used to equivalently aggregate PV power plants controlled by a synchronous power controller into one PV power generation unit. The Norton equivalent model of the PV inverter was established in [37], where the resonance phenomenon of large-scale PV power plant was analyzed, and the parameters of the inverter were equivalently aggregated. As above-mentioned, idealized capacity equal weighted situations can be equivalent to the single-machine model only on the basis of equivalent requirements with lower precision.

\subsubsection{Parameter Identification Method}

Under normal circumstances, the equivalent conditions of PV power plants cannot be idealized. At this time, the model parameters can be identified by the algorithm according to the input and output characteristics of the PV power plant, and the identified parameters are used as the parameters of the single-machine equivalent model [38]. To identify parameters for a system, the usual solution steps are as shown in Figure 2.

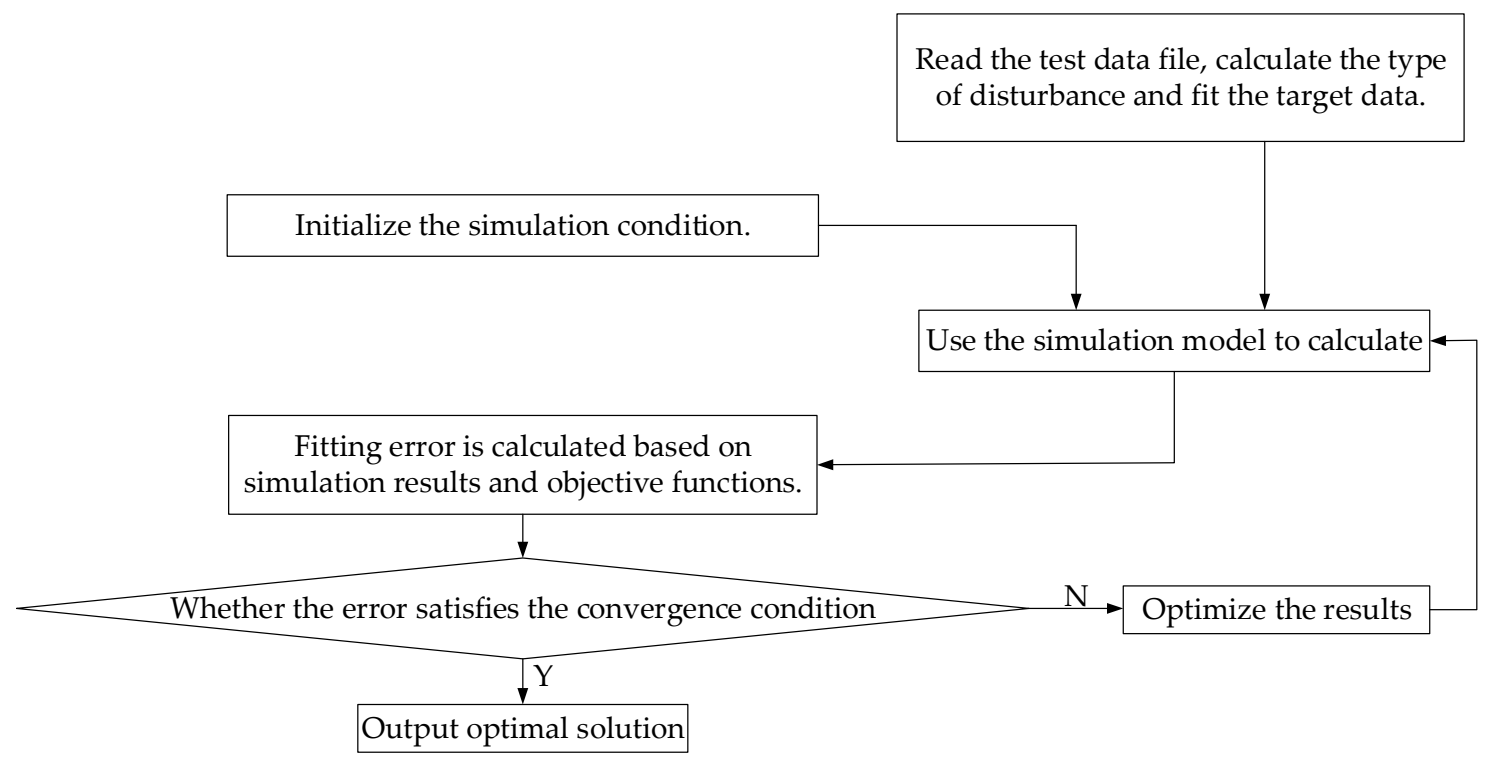

Figure 2. The steps of parameter identification.

In the study of parameter identification in PV systems, scholars have made significant progress. In [39], a linear dynamic system with multiple input and output ports was applied to PV inverters. Based on the theory of least squares, structure identification and parameter estimation of PV inverters were carried out. In [40], considering that the PV grid-connected inverter as a linear model would lead to large errors, it was proposed to consider it as a two-input and two-output nonlinear black box system. The Wiener model of a single-phase PV grid-connected inverter was obtained by using non-linear system identification technology based on the external measurement data of the direct current (DC) and alternating current (AC) sides of a grid-connected inverter. Using the single-machine 
equivalent model obtained by parameter identification to replace the detailed model of the large-scale PV power plant has higher accuracy and meets the real situation; however, this method cannot take into account the type of inverter or the internal structure of the PV power plant. The obtained equivalent model is not widely applicable.

In actual large-scale PV power plants, the types of inverters may vary. Moreover, the external environment for different PV power generation units is different. Even though the types and parameters of inverters are the same, the operating conditions may be different. The single-machine equivalence is simple and convenient. However, there is a big error in studying the dynamic response characteristics of an entire PV power plant by replacing all of the PV power generation units with one equivalent power generation unit [41]. In this case, the new equivalent method needs to be considered. On the basis of the simplification of the PV power plant equivalent model, it is important to meet the accuracy requirements by controlling the error within the scope.

\subsection{The Multi-Machine Equivalent Models of PV Power Plants}

According to the situation where the error of single-machine equivalence is large in a PV power plant, it is necessary to obtain a reasonable grouping index based on the transient response characteristics of inverters under different operating conditions and to group the PV components, establishing multi-machine equivalent models. The schematic diagram of the grouping results of PV power plants is shown as Figure 3.

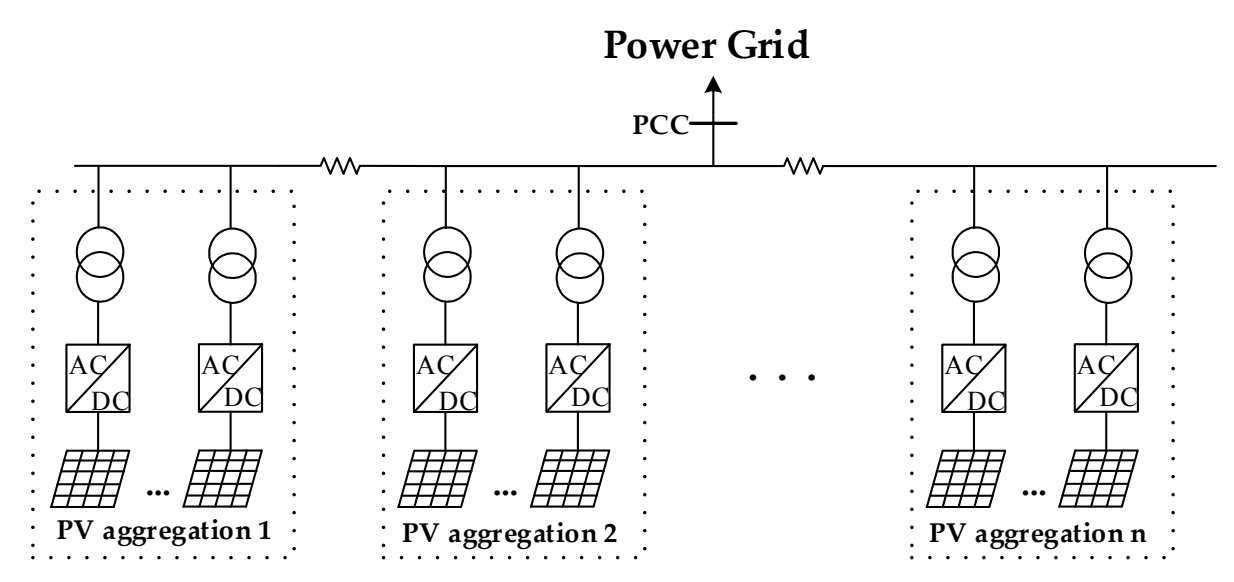

Figure 3. The schematic diagram of grouping result of a PV power plant.

In Figure 3, a large number of PV generating units in the PV power plant were divided into $n$ $(n>1)$ representative groups. The PV power generation units in the same group have similar dynamic response characteristics, while the dynamic characteristics of PV power generation units between the different groups can be different [42]. The equivalent parameters of each group were obtained, and all of the PV units in the same group were equivalent to one unit. Therefore, $n$ groups have $n$ representative units, which form a simplified $n$-unit equivalent model. This section focuses on the process of grouping PV power generation units. The calculation of the equivalent parameters of each group will be discussed in the next section.

For the equivalence of large-scale PV power plants, the core contents include the selection of grouping indexes and the choice of grouping methods. The selection of grouping indexes has a significant impact on the effect of equivalence. The indexes can be classified into three categories: feature distance based on control parameters; external characteristics; and iconic demarcation point. After selecting the grouping index, the appropriate grouping method should be chosen to group. The specific summary is shown in Table 3. 
Table 3. The multi-machine equivalent method of PV power plants.

\begin{tabular}{lllll}
\hline Equivalent Basis & Essential Feature & \multicolumn{1}{c}{ Advantages } & Disadvantages & Application Situation \\
\hline Control parameters & $\begin{array}{l}\text { Group with } \\
\text { algorithms }\end{array}$ & $\begin{array}{l}\text { Reflect the essential } \\
\text { characteristics; } \\
\text { High precision }\end{array}$ & $\begin{array}{l}\text { The control } \\
\text { parameters are } \\
\text { difficult to quantify }\end{array}$ & $\begin{array}{l}\text { Control parameters } \\
\text { are known }\end{array}$ \\
\hline $\begin{array}{l}\text { External } \\
\text { characteristics }\end{array}$ & $\begin{array}{l}\text { Group with } \\
\text { algorithms }\end{array}$ & $\begin{array}{l}\text { Can easily be measured; } \\
\text { The physical meaning } \\
\text { is clear }\end{array}$ & $\begin{array}{l}\text { cannot accurately } \\
\text { reproduce the } \\
\text { transient response } \\
\text { characteristics }\end{array}$ & $\begin{array}{l}\text { Control parameter } \\
\text { are unknown }\end{array}$ \\
\hline $\begin{array}{l}\text { Iconic } \\
\text { demarcation point }\end{array}$ & Group directly & $\begin{array}{l}\text { Eliminate the dependence } \\
\text { on the clustering algorithm }\end{array}$ & $\begin{array}{l}\text { The information of } \\
\text { boundary points is } \\
\text { difficult to obtain }\end{array}$ & $\begin{array}{l}\text { There is a definite group } \\
\text { boundary condition }\end{array}$ \\
\hline
\end{tabular}

\subsubsection{Grouping Index}

Refining the most critical grouping index from the variables in the inverter is the key to grouping the PV power plant. The grouping index needs to be able to characterize the operating conditions of units, disturbance, and the information of the network topology [43]. At present, these are the following types of reasonable grouping indexes:

(1) Feature distance based on control parameters

Taking the feature distance between all of the PV power generation units as an index to group the PV power plant is commonly used for grouping. In the same control mode, the control parameters of the inverter have a significant impact on the dynamic response characteristics of the PV power plant. The differences of the control parameters can directly reflect their different dynamic characteristics [44]. Therefore, the distance between the vector of parameters of every two inverters can be used as the feature distance. Using control parameters to group is accurate, but the index is difficult to obtain and quantify. The practical application of taking feature distance based on control parameters as the grouping index is shown in Table 4.

Table 4. The index of feature distance based on the control parameters.

\begin{tabular}{|c|c|c|}
\hline Grouping Index & Practical Application & Results \\
\hline \multirow{4}{*}{$\begin{array}{l}\text { Feature distance } \\
\text { based on control } \\
\text { parameters }\end{array}$} & $\begin{array}{l}\text { Multiply control parameters by the sensitivity } \\
\text { coefficient of parameters [41] }\end{array}$ & $\begin{array}{l}\text { Improved index can fully reflect the impact } \\
\text { of control parameters on the system }\end{array}$ \\
\hline & $\begin{array}{l}\text { Establish an offline database of parameter } \\
\text { sensitivity and reference response curves [44] }\end{array}$ & Increasing adaptability to actual conditions \\
\hline & $\begin{array}{l}\text { The indexes of feature distance are calculated } \\
\text { respectively for PI control (proportional integral) } \\
\text { and low voltage control strategy [45] }\end{array}$ & $\begin{array}{l}\text { The disturbance conditions of different } \\
\text { control strategies are separated to improve } \\
\text { the equivalent precision }\end{array}$ \\
\hline & $\begin{array}{l}\text { The filter inductance coefficient of PV inverter is } \\
\text { included in the indexes of feature distance [46] }\end{array}$ & $\begin{array}{l}\text { The dynamic response characteristics of the } \\
\text { inverter are fully reflected }\end{array}$ \\
\hline
\end{tabular}

\section{(2) External characteristics}

Using the output external characteristics of the PV inverter as grouping indexes is a more direct method for grouping. External characteristics generally include active power, reactive power, output voltage, and output current. Active power and reactive power are the integrated manifestation of voltage and current, which are more representative in the indicators of the transient response characteristics of the inverter. Therefore, the active power and reactive power are more commonly used as the grouping indexes of PV power plants. It is also considered that the reactive power at the point of common coupling (PCC) can be adjusted not only by the PV inverter itself, but also by the reactive power compensation device. Therefore, compared with reactive power, active power is more appropriate to analyze the transient response characteristics. In [47], it was considered that 
current and active power play an important role in the fault response characteristics. The clustering characteristics of active power and current transient response curves were analyzed. In order to prevent the impact of the sudden change of active power on the PV units and power grid at the moment of fault removal, active power slope recovery control can be added after fault removal [48]. In view of the control strategy considering the active power slope recovery of the inverter, Fan measured the active power output of each PV power generation unit in real time. The PV power generation units were divided into three groups: high-power condition, medium-power condition, and low-power condition. The final results were obtained by group correction and the equivalence model had good adaptability to the disturbance of light intensity, fault time, and fault location [49]. However, when the control parameters of the inverter are inconsistent, the output external characteristics may not accurately reflect the transient response of the PV power generation units, and the equivalent precision will be greatly deviated. The question of how to find a grouping index that can accurately reproduce the transient response characteristics of a PV power plant is the key to the equivalence modeling research.

(3) Iconic demarcation point

Using output external characteristics or control parameters to group PV power generation units needs the use of a clustering algorithm to deal with the data. The characteristics of the margins in each group have a certain error and the equivalence accuracy is not high. Therefore, looking for the grouping basis with higher accuracy, that is, using the iconic demarcation point to group, is an important branch of the equivalence modeling research. In doubly-fed induction generator (DFIG) wind farms, the action of crowbar protection during the fault is the principle of grouping to establish the equivalent model of wind farms [50]. In [51], Tang proposed a control strategy of adding a DC-chopper protection circuit on the DC side of the inverter in light of the operation characteristics of the PV power plant at a low voltage ride through. Figure 4 shows the DC-chopper protection in the PV power generation unit, which is constituted by the unloading resistance. An Insulated Gate Bipolar Transistor (IGBT) switch is used to connect the unloading resistance to the DC side circuit or remove it according to the voltage signal to control the opening or closing of the protection circuit.

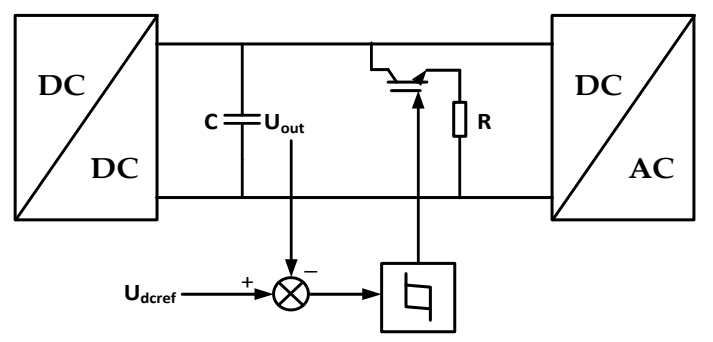

Figure 4. DC-chopper protection circuit.

The PV power plants can be divided into three groups according to the different actions caused by the DC bus voltage changes as well as the unloading resistance operation states during the fault: the unloading resistance turns on; the DC bus voltage increases but the unloading circuit operation threshold is not reached when the fault is removed; and the DC bus voltage slightly fluctuates around the normal value [52]. Using the protection circuit or the switching state of the unloading resistance to group, which has an iconic demarcation point and accurate grouping results, eliminates the dependence on the clustering algorithm. However, it is difficult to find the iconic demarcation point as the information of boundary points is difficult to obtain and some operational characteristics are not considered. 


\subsubsection{Grouping Method}

After obtaining the grouping indexes, the PV power plants need to be grouped according to the index. The clustering algorithm or operating state of units can be used to group. Clustering is the process of dividing a large amount of data into several different groups. For a PV power plant, the clustering task is completed by determining the similarity of the previously selected grouping indexes in the data attributes, so that the similarity of feature vectors of the same group is larger than that of different groups $[53,54]$. The essence of grouping by the operating state of units is to use the iconic demarcation point to group. A comparison of the grouping methods is shown in Table 5.

Table 5. The comparison of grouping methods.

\begin{tabular}{|c|c|c|c|}
\hline $\begin{array}{l}\text { The Basis of the } \\
\text { Grouping Method }\end{array}$ & Features & Practical Example & Results \\
\hline \multirow{4}{*}{$\begin{array}{l}\text { Clustering } \\
\text { algorithm }\end{array}$} & \multirow{4}{*}{$\begin{array}{l}\text { Grouping data } \\
\text { indexes by } \\
\text { algorithm }\end{array}$} & K-means clustering [42] & $\begin{array}{l}\text { Fast speed; The accuracy is easily affected by the } \mathrm{K} \\
\text { value }\end{array}$ \\
\hline & & Fuzzy clustering $[41,55]$ & $\begin{array}{l}\text { Accurate; Complex calculations, not suitable for } \\
\text { large samples }\end{array}$ \\
\hline & & Spectral clustering $[56,57]$ & $\begin{array}{l}\text { Suitable for clustering on any shape of sample } \\
\text { space; Sensitive to parameters }\end{array}$ \\
\hline & & $\begin{array}{l}\text { SVM (support vector } \\
\text { machine) clustering [58] }\end{array}$ & $\begin{array}{l}\text { Small sample; Avoids dimension disasters; } \\
\text { Not applicable to large samples and } \\
\text { multiple categories }\end{array}$ \\
\hline \multirow{2}{*}{ Operating state } & \multirow{2}{*}{$\begin{array}{l}\text { Grouping by iconic } \\
\text { demarcation point }\end{array}$} & $\begin{array}{l}\text { The action of protection } \\
\text { circuit [50]; }\end{array}$ & \multirow{2}{*}{$\begin{array}{l}\text { Eliminates the dependence on the } \\
\text { clustering algorithm; } \\
\text { The operating state is difficult to evaluate; } \\
\text { Some operational characteristics are not considered }\end{array}$} \\
\hline & & $\begin{array}{l}\text { The switching state of the } \\
\text { unloading resistance }[51,52]\end{array}$ & \\
\hline
\end{tabular}

In the research of PV power plant equivalence modeling, the k-means clustering algorithm has been more commonly used, but the result of the grouping obtained by this method is greatly affected by the $\mathrm{k}$ value, which increases the uncertainty of the equivalent model. Fuzzy clustering is a mathematical method for classifying objective things by establishing fuzzy similar relations [55]. In [41], the traditional fuzzy C-means (FCM) algorithm had the defects of unreasonable initialization of the membership matrix. The improved FCM algorithm was used to realize the dynamic clustering of PV inverters. The objective functions of generic membership function and FCM algorithm were established, and the grouping results were obtained by iteratively solving the optimal clustering center and fuzzy membership matrix. Using the spectral clustering algorithm based on the diffusion mapping theory to group the actual operation data of the PV power generation units, the similarity of the dynamic response between the units can also be found to perform the equivalence modeling $[56,57]$. In order to deal with the clustering of $\mathrm{PV}$ power plants under different operating conditions, a more advanced and operational SVM clustering algorithm can be selected. In [58], Teng improved the traditional homology equivalence method by analyzing real time operating data, and proposed a covariate equivalence method based on SVM, and verified the accuracy and robustness of the SVM classifier. A detailed description of grouping by operating state of units has been provided in Section 4.2.1. It can eliminate the dependence on the clustering algorithm and group accurately; however, sometimes the operating state is difficult to evaluate and some operational characteristics such as active power may not be considered.

\section{Calculation of Equivalent Parameters}

After grouping the PV power generation units in the PV power plant, it is necessary to calculate the equivalent parameters of each group in multi-machine equivalence in order to better simulate the dynamic response process of the PV power plant in transient stability analysis. Equivalent parameters are generally calculated by capacity equal weighting and parameter identification $[59,60]$. 


\subsection{Capacity Equal Weighted Method in Multi-Machine Equivalence}

The capacity equal weighted method is used to deal with the parameters of inductors, capacitors, transformers, and PV arrays in PV power plants. The core idea is the same as the capacity equal weighted method in Section 4.1.1. The capacity equal weighted method using the multiplication idea can effectively reduce the difficulty of computing the parameters of the equivalent model. However, this method needs to be based on more accurate grouping. In actual cases, there may be large errors regarding the equivalent parameters calculated by the capacity equal weighted method, and the simulated characteristic curves are quite different from the detailed models [61].

\subsection{Parameter Identification Method in Multi-Machine Equivalence}

In light of the defect where the capacity equal weighting is too idealized, parameter identification can be used to obtain the parameters of the PV equivalent model. The parameters of equivalent model are identified based on PV system models such as the linear dynamic system and the nonlinear black box system, as described in Section 4.1.2. In addition, using a parameter identification algorithm to identify and optimize the equivalent parameters to improve the fitting precision of the characteristic of the PV power plant was also the current focus of the study. Generally, the important parameters of the equivalent model can be identified by the genetic algorithm, while the secondary parameters can be determined by statistical synthesis [62]. If the particle swarm optimization algorithm is used to identify the unknown parameters step by step in the PV equivalent model, the equivalence accuracy is high, but the process of calculation is complicated [63].

\section{Equivalence of Power Collection System}

The dynamic influence of the PV power plant power collection system mainly comes from the topology of the PV power plant and the length of the line as well as some electrical equipment such as transformers and loads. The equivalence of the power collection system is based on the principle of constant impedance loss and constant voltage at PCC [64]. In general, the topological structure of the PV power plant should be considered, as shown in Figures 5 and 6, and the equivalent impedance and equivalent admittance of the power collection line of the trunk topology and the radial topology are calculated respectively [49].

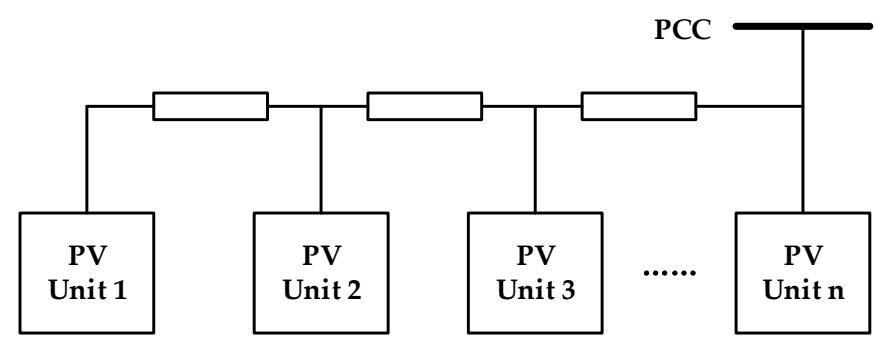

Figure 5. Trunk topology of a PV power plant.

PCC

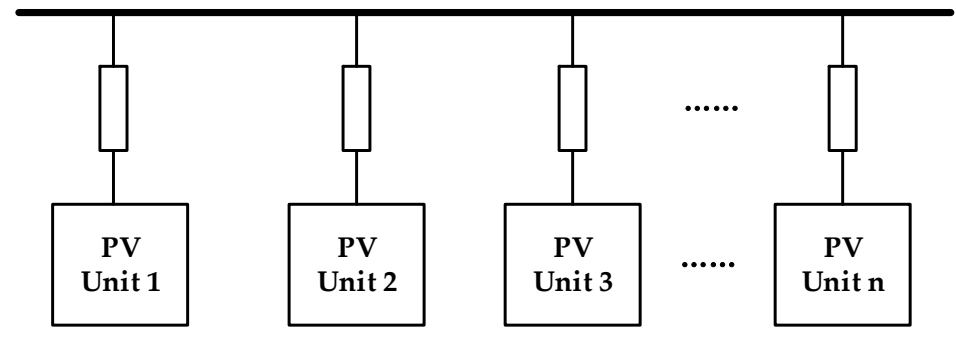

Figure 6. Radial topology of PV power plant. 
According to circuit theory, Chen carried out the equivalent calculation of the line impedance based on the principle that the power loss of the power collection system is constant and the reactive power at PCC is consistent during the fault [65]. Taking the equivalence of internal fault into consideration, the original topology and parameters of the power collection line were reserved, and the location where the equivalent unit was connected to the power collection line was determined through nonlinear programming [66].

\section{Conclusions}

This paper focused on the equivalence modeling of a large-scale PV power plant, and expounded the steady-state equivalent model and transient equivalent model, respectively. The single-machine equivalence and multi-machine equivalence in transient equivalence were introduced emphatically. Aiming at the selection of grouping indexes and grouping methods in multi-machine equivalence, a detailed description was given. A brief introduction to the calculation of equivalent parameters and the equivalence of power collection system was also given. At present, the research on equivalence modeling of the PV power plant is still limited to a relatively few studies, and many problems need to be found and solved urgently. According to the current research status, there are several aspects that need further research and improvement:

(1) How to extract the most critical grouping index in operational variables to make the grouping result more accurate and reasonable. It is difficult to characterize the transient characteristics of the PV power generation units comprehensively through the existing grouping indexes. Whether it can be combined with statistical principles and principal component analysis to extract the main features for equivalence modeling is worth studying.

(2) In practical projects, due to the fact that some modules of the model are encapsulated, the corresponding grouping indexes cannot be measured and acquired. The question of how to extract easily observed variables based on engineering practice as grouping indexes needs to be solved.

(3) How to establish a dynamic equivalent model of PV power plant considering environmental changes in longer time scales.

(4) When the location or the type of fault is changed, it is debatable whether the original equivalent model is applicable. Finding the equivalent method suitable for various fault conditions and simulating the transient response characteristics accurately needs to be further explored.

(5) Validation of models, model standardization, and evaluation indicators of models still require further improvement.

Author Contributions: This paper was a collaborative effort between the authors. The authors contributed collectively to the collation and review of literatures.

Acknowledgments: This paper is based on the China National Key Research and Development Plan "Smart Grid and Equipment" (2016YFB0900600) and Project Supported by Science and Technology Foundation of State Grid Corporation of China (52110417000F).

Conflicts of Interest: The authors declare no conflict of interest.

\section{References}

1. Zhou, L.P. Research on Current Situation and Development Strategy of China's Photovoltaic Industry. Hebei Enterp. 2018, 3, 80-81. [CrossRef]

2. Hu, R.Q. Review and Prospects of Photovoltaic Power Market in 2017. Sol. Energy 2018, 1, 14-18.

3. Khoury, J.; Mbayed, R.; Salloum, G.; Monmasson, E.; Guerrero, J. Review on the integration of photovoltaic renewable energy in developing countries-Special attention to the lebanese case. Renew. Sustain. Energy Rev. 2016, 57, 562-575. [CrossRef] 
4. Ding, M.; Zhang, Y.; Han, P.; Bao, Y.; Zhang, H. Research on Optimal Wind Power Penetration Ratio and the Effects of a Wind-Thermal-Bundled System under the Constraint of Rotor Angle Transient Stability. Energies 2018, 11, 666. [CrossRef]

5. Bialasiewicz, J.T. Renewable energy systems with photovoltaic power generators: Operation and modeling. IEEE Trans. Ind. Electr. 2008, 55, 2752-2758. [CrossRef]

6. Zhu, Y.; Hao, J.; Li, X.; Tang, Q.; Xia, R. Research on harmonic and overvoltage of photovoltaic power plant electricity energy collection system based on passive network model. J. Eng. 2017, 13, 789-794. [CrossRef]

7. Merten, J.; Asensi, J.M.; Voz, C.; Shah, A.V.; Platz, R.; Andreu, J. Improved equivalent circuit and analytical model for amorphous silicon solar cells and modules. IEEE Trans. Electron Devices 1998, 45, 423-429. [CrossRef]

8. Meinhardt, M.; Cramer, G.; Burger, B.; Zacharias, P. Multi-string-converter with reduced specific costs and enhanced functionality. Sol. Energy 2001, 69, 217-227. [CrossRef]

9. Ma, J.; Zhao, D.W.; Qian, M.H.; Zhu, L.Z.; Geng, H. Modelling and validating photovoltaic power inverter model for power system stability analysis. J. Eng. 2017, 2017, 1605-1609. [CrossRef]

10. Tapia, R.; Fuerte-Esquivel, C.R.; Espinosa-Juarez, E.; Sandoval, U. Steady-state model of grid-connected photovoltaic generation for power flow analysis. IEEE Trans. Power Syst. 2018, in press. [CrossRef]

11. Remon, D.; Cantarellas, A.M.; Rodriguez, P. Equivalent model of large-scale synchronous photovoltaic power plants. IEEE Trans. Ind. Appl. 2016, 52, 5029-5040. [CrossRef]

12. Samadi, A.; Söder, L.; Shayesteh, E.; Eriksson, R. Static equivalent of distribution grids with high penetration of PV systems. IEEE Trans. Smart Grid 2015, 6, 1763-1774. [CrossRef]

13. Ge, J.B.; Zhou, M.; Li, G.Y. Review on large-scale wind farm modeling. Power Syst. Prot. Control 2013, 41, $146-153$.

14. Zhou, H.Q.; Song, Z.P.; Wang, J.P.; Xue, Y. A Review on Dynamic Equivalent Methods for Large Scale Wind Farms. In Proceedings of the 2011 Asia-Pacific Power and Energy Engineering Conference (APPEEC), Wuhan, China, 25-28 March 2011; pp. 1-7.

15. Yao, H.; Zhou, J.; Huang, Z.; Cao, L.; Yang, W.; Xu, T. A practicable method for dynamic equivalence. Autom. Electr. Power Syst. 2009, 33, 111-115. [CrossRef]

16. Luo, A.; Xie, N.; Shuai, Z.; Chen, Y. Large-scale photovoltaic plant harmonic transmission model and analysis on resonance characteristics. IET Power Electr. 2015, 8, 565-573. [CrossRef]

17. Liu, D.; Chen, S.; Ma, M.; Wang, H.; Hou, J.; Ma, S. A review on models for photovoltaic generation system. Power Syst. Technol. 2011, 35, 47-52.

18. Liu, J.; Huang, W. Analysis on grid-connectible capacity of distributed PV generation in case of PV generation distribution close to load distribution. Power Syst. Technol. 2015, 39, 299-306.

19. Yang, M.; Zhou, L.; Du, X.; Wei, Y.F.; Li, B. Reactive power and voltage control in the large photovoltaic power plants. Electr. Mach. Control 2016, 20, 70-81.

20. Biswas, P.P.; Suganthan, P.N.; Amaratunga, G.A.J. Optimal power flow solutions incorporating stochastic wind and solar power. Energy Convers. Manag. 2017, 148, 1194-1207. [CrossRef]

21. Wang, S.X.; Huang, L.J.; Wang, C.S.; Li, D. Unbalanced three-phase power flow calculation for distributed power generation system. Electr. Power Autom. Equip. 2007, 8, 11-15. [CrossRef]

22. Guo, Y.; Zhang, B.; Wenchuan, W.U. Study on bus-type extended load flow and its solvability. Proc. CSEE 2011, 31, 79-85.

23. Ding, M.; Xu, Z.; Wang, W.; Wang, X.; Song, Y.; Chen, D. A review on China's large-scale PV integration: Progress, challenges and recommendations. Renew. Sustain. Energy Rev. 2016, 53, 639-652. [CrossRef]

24. Dan, L.I.; Chen, H.Y. Algorithm research of load flow of distribution network with different distributed generations. East China Electr. Power 2011, 39, 76-80.

25. Wang, Y.; Wu, C.; Liao, H.; Xu, H. Steady-state power flow analyses of large-scale grid-connected photovoltaic generation system. J. Tsinghua Univ. 2009, 49, 1093-1097. [CrossRef]

26. Zhang, F.; Li, H.; Zhang, L. Power flow calculation model of PQ coupling photovoltaic and influence of photovoltaic on distribution network voltage. J. Electr. Eng. 2016, 11, 1-6.

27. Du, X.; Zhou, L.; Guo, K.; Yang, M.; Liu, Q.; Shao, N. Static voltage stability analysis of large-scale photovoltaic plants. Power Syst. Technol. 2015, 39, 3427-3434.

28. Bonfiglio, A.; Delfino, F.; Invernizzi, M.; Procopio, R.; Serra, P. An approximate methodology to verify the compliance of large photovoltaic power plants to system operator steady-state requirements. Electr. Power Syst. Res. 2015, 127, 80-92. [CrossRef] 
29. Bonfiglio, A.; Delfino, F.; Invernizzi, M.; Procopio, R.; Serra, P. Criteria for the equivalent modeling of large photovoltaic power plants. In Proceedings of the 2014 IEEE PES General Meeting I Conference \& Exposition, National Harbor, MD, USA, 27-31 July 2014; pp. 1-5.

30. Vittal, V.; Ma, F. A hybrid dynamic equivalent using ANN-based boundary matching technique. IEEE Trans. Power Syst. 2012, 27, 1494-1502. [CrossRef]

31. Li, H.; Pang, S.L.; Huang, J.D. Equivalent modeling and simulation of large photovoltaic station. Appl. Mech. Mater. 2014, 615, 27-30. [CrossRef]

32. Yan, K.; Zhang, B.; Qu, J.; Wu, X. Photovoltaic power system transient modeling and equivalents. Power Syst. Prot. Control 2015, 43, 1-8. [CrossRef]

33. Pan, X.; Zhang, Y.; Ju, P.; Jin, Y.; Liu, T.; Zeng, P. Equivalent modeling for photovoltaic power station. Power Syst. Technol. 2015, 39, 1173-1178.

34. Wang, H.; Tang, Y.; Hou, J.; Zou, J.; Liang, S.; Su, F. Composition modeling and equivalence of an integrated power generation system of wind, photovoltaic and energy storage unit. Proc. CSEE 2011, 31, 1-9.

35. Wang, H.; Tang, Y.; Hou, J.; Liu, N.; Li, B.; Zhang, H. Equivalent method of integrated power generation system of wind, photovoltaic and energy storage in power flow calculation and transient simulation. Proc. CSEE 2012, 32, 1-8.

36. Remon, D.; Cantarellas, A.M.; Elsaharty, M.A.A.; Koch-Ciobotaru, C.; Rodriguez, P. Equivalent model of a synchronous PV power plant. In Proceedings of the 2015 IEEE Energy Conversion Congress and Exposition (ECCE), Montreal, QC, Canada, 20-24 September 2015; pp. 47-53.

37. Lin, Z.; Mi, Z. Analysis of resonance phenomenon in large-scale photovoltaic power plant. Electr. Power Autom. Equip. 2014, 34, 8-14. [CrossRef]

38. Omar, A.; Hasanien, H.M.; Elgendy, M.A.; Badr, M.A.L. Identification of the photovoltaic model parameters using the crow search algorithm. J. Eng. 2017, 13, 1570-1575. [CrossRef]

39. Xiong, X.F.; Chen, K.; Zheng, W.; Shen, Z.J.; Shahzad, N.M. Photovoltaic inverter model identification based on least squares method. Power Syst. Prot. Control 2012, 40, 52-57. [CrossRef]

40. Zheng, W.; Xiong, X.F. A model identification method for photovoltaic grid-connected inverters based on the wiener model. Proc. CSEE 2013, 33, 18-26.

41. Sheng, W.X.; Ji, Y.; Wu, M.; Liu, H.T.; Kou, L.F.; Sun, L.J. Dynamic clustering modeling of regional centralized photovoltaic power plant based on improved fuzzy C-means clustering algorithm. Power Syst. Technol. 2017, 41, 3284-3291.

42. Chen, S.; Wang, C.; Shen, H.; Gao, N.; Zhu, L.; Lan, H. Dynamic equivalence for wind farms based on clustering algorithm. Proc. CSEE 2012, 32, 11-19.

43. Xu, J.B.; Xue, Y.S.; Zhang, Q.P.; Wang, D.X. Critical review on coherency-based dynamic equivalences. Autom. Electr. Power Syst. 2005, 29, 91-95. [CrossRef]

44. Cui, X.D.; Li, W.; Li, Z.W.; Fang, Y.J.; Xue, Y.S.; Xue, F. An online dynamic equivalent method for large-scale photovoltaic power plant suitable for electromechanical transient stability simulation. Autom. Electr. Power Syst. 2015, 39, 21-26. [CrossRef]

45. Li, C.L.; Wang, J.; Yang, L.B. Equivalent modeling research and application of typical grid connected photovoltaic power station. Electr. Power Constr. 2015, 36, 114-121. [CrossRef]

46. Ma, Z.; Zheng, J.; Zhu, S.; Shen, X.; Wei, L.; Wang, X. Online clustering modeling of large-scale photovoltaic power plants. In Proceedings of the 2015 IEEE Power \& Energy Society General Meeting, Denver, CO, USA, 26-30 July 2015; pp. 1-5.

47. Li, W.; Chao, P.; Liang, X.; Xu, D.; Jin, X. An improved single-machine equivalent method of wind power plants by calibrating power recovery behaviors. IEEE Trans. Power Syst. 2017, in press. [CrossRef]

48. Li, W.; Chao, P.; Liang, X.; Ma, J.; Xu, D.; Jin, X. A practical equivalent method for DFIG wind farms. IEEE Trans. Sustain. Energy 2017, 9, 610-620. [CrossRef]

49. Fan, S.C. Investigation on Equivalent Modeling of Photovoltaic Power Plants; Harbin Institute of Technology: Harbin, China, 2016.

50. Zhu, Q.L.; Ding, M.; Han, P.P. Equivalent modeling of DFIG-based wind power plant considering crowbar protection. Math. Probl. Eng. 2016, 1-16. [CrossRef]

51. Tang, B.W.; Yuan, T.J.; Chao, Q.; Yi-Bulayin, T. Analysis of LVRT of grid-connected PV system based on dc-chopper protection. Chin. J. Power Sources 2013, 37, 2016-2018. [CrossRef] 
52. Yang, P.; Sun, L.; Wu, N. Simulation research of doubly fed induction wind generator to achieve LVRT. Electr. Power Sci. Eng. 2012, 28, 8-14. [CrossRef]

53. Germond, A.J.; Podmore, R. Dynamic aggregation of generating unit models. IEEE Trans. Power Appar. Syst. 1978, PAS-97, 1060-1069. [CrossRef]

54. Li, S.; Liu, Z.; Hao, X.; Jia, S. Dynamic equivalence to induction generators and wind turbines for power system stability analysis. In Proceedings of the 2010 2nd IEEE International Symposium on Power Electronics for Distributed Generation Systems (PEDG), Hefei, China, 16-18 June 2010; pp. 887-892.

55. Yan, C.; Xiu, J.; Liu, C.; Yang, Z. A high concentrated photovoltaic output power predictive model based on Fuzzy Clustering and RBF neural network. In Proceedings of the 2014 IEEE 3rd International Conference on Cloud Computing and Intelligence Systems (CCIS), Shenzhen, China, 27-29 November 2014; pp. 384-388.

56. Lin, L.; Chen, Y.; Wang, N. Clustering wind turbines for a large wind farm using spectral clustering approach based on diffusion mapping theory. In Proceedings of the 2012 IEEE International Conference on Power System Technology (POWERCON), Auckland, New Zealand, 30 October-2 November 2012; Volume 6, pp. 1-6.

57. Yuan, Z.; Hao, L.; Dai, J. Overview of the equivalent model research for wind farms. Power Syst. Prot. Control 2015, 43, 138-146. [CrossRef]

58. Teng, W.; Wang, X.; Xiao, Y.; Shi, W. Dynamic multi-turbine multi-state model of wind farm based on historical wind data. In Proceedings of the 2014 IEEE PES Asia-Pacific Power and Energy Engineering Conference (APPEEC), Hong Kong, China, 7-10 December 2014; pp. 1-5.

59. Li, P.; Gu, W.; Wang, L.; Xu, B.; Wu, M.; Shen, W. Dynamic equivalent modeling of two-staged photovoltaic power station clusters based on dynamic affinity propagation clustering algorithm. Int. J. Electr. Power Energy Syst. 2018, 95, 463-475. [CrossRef]

60. Matevosyan, J.; Villanueva, S.M.; Djokic, S.Z.; Acosta, J.L.; Zali, S.M.; Resende, F.O. Aggregated models of wind-based generation and active distribution network cells for power system studies-Literature overview. In Proceedings of the 2011 IEEE Trondheim PowerTech, Trondheim, Norway, 19-23 June 2011; pp. 1-8.

61. Zou, J.; Peng, C.; Yan, Y.; Zheng, H.; Li, Y. A survey of dynamic equivalent modeling for wind farm. Renew. Sustain. Energy Rev. 2014, 40, 956-963. [CrossRef]

62. Wu, F.; Li, W. Dynamic equivalence analysis of distribution network integrated with high-penetration distributed photovoltaic generation system. Autom. Electr. Power Syst. 2017, 41, 65-70.

63. Sun, L.; Lin, X.; Jin, Y.; Lei, P.; Shi, H. Modeling of grid-connected photovoltaic generation unit based on particle swarm optimization algorithm. Power Syst. Technol. 2015, 39, 1213-1218.

64. Zou, J.; Peng, C.; Xu, H.; Yan, Y. A fuzzy clustering algorithm-based dynamic equivalent modeling method for wind farm with DFIG. IEEE Trans. Energy Convers. 2015, 30, 1329-1337. [CrossRef]

65. Chen, Z.; Xia, A.; Wang, N.; Ying, Q.; Ma, Y. Collector network equivalent method of wind farm for low voltage ride through simulation. Autom. Electr. Power Syst. 2016, 40, 51-56. [CrossRef]

66. Lu, F.; Liu, Q.; Zhao, Y.; Song, S. Equivalent modeling method for wind farm inner fault based on demagnetizing control of low voltage ride through. Autom. Electr. Power Syst. 2016, 40, 24-30. [CrossRef]

(c) 2018 by the authors. Licensee MDPI, Basel, Switzerland. This article is an open access article distributed under the terms and conditions of the Creative Commons Attribution (CC BY) license (http:/ / creativecommons.org/licenses/by/4.0/). 